\section{PEGylierte Proteine}

R. Westermeier

Freising, Deutschland

Synonym(e) Mit Polyethylenglykol konjugierte Proteine

\section{Englischer Begriff PEGylated Proteins}

Definition Artifizielle Modifikation von Proteinen durch Konjugation mit Polyethylenglykol (PEG).

Beschreibung Durch PEGylierung werden therapeutische Proteine mit Polyethylenglykol (PEG) konjugiert. Dabei werden die kettenförmigen PEG-Moleküle an den biopharmazeutischen Wirkstoff angehängt, die das Proteinmolekül fast vollständig einbetten und somit bei der therapeutischen Anwendung gegen vorzeitigen Abbau durch Antikörper oder körpereigene Proteasen schützen. Die wichtigsten Effekte sind hierbei die verringerte Immungenität und die Vergröße- rung der bei der Humantherapie verwendeten Moleküle der biopharmazeutischen Wirkstoffe wie z. B. Interferone, Erythropoetin, Hormone, Wachstumsfaktoren und rekombinante Antikörperfragmente. Letzteres führt zu einer deutlich verlangsamten renalen Ausscheidung.

Allerdings werden solche Wirkstoffe auch für Doping eingesetzt, wie z. B. synthetisches Erythropoietin. PEGylierte Proteine verursachen Probleme bei der Dopingkontrolle mit SDS-Elektrophorese und Western Blotting zur Differenzierung des körpereigenen Hormons vom synthetischen Erythropoietin in Human-Urinproben. Der generell verwendete Anti-EPO-Antikörper interagiert nicht mit den komplett mit SDS beladenen PEGylierten Molekülen.

\section{Literatur}

Abuchowski A, McCoy JR, Palczuk NC, van Es T, Davis FF (1977) Effect of covalent attachment of polyethylene glycol on immunogenicity and circulating life of bovine liver catalase. J Biol Chem 252:3582-3586 